\title{
Learning to Count
}

\author{
MARY CATHERINE BATESON, Cultural Anthropologist
}

[Editor's note: this is a reworking of Mary Catherine Bateson's original piece on "Making a Difference", which was the foreword to the Springer Handbook of Human Computation (2013).]

One of the mysteries of our species, now approaching eight billion persons, is the very limited way in which the intelligence of this vast number of individuals can be said to add up or combine. On the one hand, every society has a body of knowledge that is passed on from generation to generation, with frequent borrowing from neighbors and gradual enrichment with new information and new understanding. Human history can even be seen as the steady process of discovering ways to store and pass on information and ideas. On the other hand, differing ideas lead to failures to cooperate and misunderstandings, complicated by the emphasis on competition and the notion that knowledge and ideas are a form of property. All these wonderful brains operate in various degrees of separation, so that neither nations nor the species as a whole has the benefit of their combined power. Do we - that is to say, all members of the human species together - have the intelligence to order our living in such a way as to preserve the viability of our planet? Surely. Do we have the capacity to integrate that intelligence, to mobilize its combined potential toward that goal, and to act on it? Not yet.

The question has been around for a long time. The myth of the Tower of Babel in Genesis is evidence of long ago puzzlement about the human difficulty in coordinating creative action with inadequate communication. In our day, when massive computing power is wanted, the solution tends to be parallel processing - multiple separate computers linked together. Early census collections were undoubtedly collated by groups of clerks toiling side by side, perhaps a little like the "boiler rooms" in which multiple salesmen make cold calls to potential investors. But setting computers or clerks side by side, while it makes it possible to crunch huge quantities of data, does not offer a model for benefiting from the diversity of different human minds complementing each other. Voting is a form of human computation that requires the same kind of input from multiple individuals in order to make a choice. Polling collates simple answers to the same question, shorn of reflection. Neither of these procedures generates new ideas. 
The field of human computation, then, has two faces. On the one hand, there is the aggregation of the effort of many different persons doing the same task or making similar inputs from different places, perhaps in-putting data about observations of threatened species or meteorological phenomena. On the other hand, there is the potential for the integration of multiple different kinds of input coming from diverse individuals to produce new and creative possibilities. This is ideally done in conversation where the participants are stimulated by their diverse points of view, aiming to discover new alternatives or to arrive at a consensus, to become "of one mind." When the numbers involved make conversation awkward, the integration process can be assisted by technology.

Thus, there have been in recent decades a wide variety of proposed methods for facilitating productive conversation that may then be collated electronically. Even when the inputs are similar in kind, there is the possibility that the aggregation of multiple responses can be an important step toward solving a fundamental ethical problem in human society, namely the increasingly widespread conviction that "nothing I can do will make any difference." Kant's Categorical Imperative ${ }^{1}$ was an attempt to solve the problem by eliminating the question of scale and proposing that an action be evaluated as if it were universal, but this has not proved particularly effective in ever larger populations. The problem of taking responsibility for individual and local actions is most severe at the global level. Thus, for instance, individuals have difficulty believing that leaving an extra electric light burning in their suburban backyard is connected to the likelihood of lethal storms thousands of miles away. Exactly the same kind of reasoning discourages voters from going to the polls for local elections. How will people learn that what they do "counts"? By counting. Similarly, the endless series of petitions posted on the Internet and the more and more frequent demands to "rate our service," are intended to give people the sense of contributing to common goals. The Vatican recently invited bishops to poll the faithful, and many responded and hope that their opinions will be heard and integrated in decision-making - that their words would really count.

We badly need models of interdependence and connectivity that will convey to those who work with them the conviction that individual voices and actions do indeed count, a message conveyed through many different modalities. It is impossible to cultivate a sense of responsibility without such a conviction. It also seems probable that ethics is meaningless without an understanding of the different kinds of causation, including indirect, multiple, and circular causation. Human computation for socially useful goals will depend on giving individuals a sense of agency - a sense that they indeed can make a difference - and a sense of how different kinds of action interact for good or for ill.

\footnotetext{
1 "There is, therefore, only one categorical imperative. It is: Act only according to that maxim by which you can at the same time will that it should become universal law." Immanuel Kant, Foundations of the Metaphysics of Morals, trans. Lewis W. Beck, ed. Robert P. Wolff, section 2, p. 44.
} 
Agency has been the central issue for the development of patient activism, both spurring research and leading to better prevention and intelligent compliance, so enrolling patients as active collaborators in research has been an important new model for citizen science. One of the earliest examples of citizen science was the St. Louis baby tooth collection organized by Barry Commoner, in which scientists "took over the tooth fairy" (Bateson, 1972) to demonstrate the dangers of nuclear testing in the atmosphere. The demonstration that Strontium 90 was being transferred in mothers' milk was a significant element in the banning of atmospheric testing, but so no doubt was the engagement it evoked in the parents.

There is a long history, going back to the Greeks and Romans, of attempting to use voting (an early form of human computation), with various modifications, to create a sense of agency that supports responsibility, and some of the hazards are known. It is not enough for bishops to hand out (or post) questionnaires: people must be convinced that they read them. Experience suggests that plebiscites are easily manipulated by autocrats (as in the rise of fascism), so that it makes more sense to vote for individuals who are then able to deliberate together about issues and act systemically as surrogate decision makers in a second round of voting than it does to decide policy by majority popular vote, thus combining computation with the integrative potential of conversation. Other variations such as proportional representation also attempt to avoid the dangers of simple majority rule. Voter initiatives may appear to increase democracy but when overused may lock in dysfunctional policies. Ventures into human computation need to be evaluated with an eye to whether the inclusion of multiple inputs will lead to better and potentially wiser decisions. And all such ventures should contain provision for feedback. A friend tells me that she spends an hour every morning signing petitions (on the Internet). Real feedback is rare - the usual, not very reinforcing reward is generally a demand for donations but Walgreen's did apparently give up the decision to move its corporate address out of the US in response to an Internet petition, and this news went out to all signers.

A central promise of human computation, already partially realized, is the possibility of creating an awareness of the vast number of decisions we all make every day, including the decision involved in where attention is focused from minute to minute (Jackson, 2009), along with information about the aggregate effect of those decisions and how they are shifting. Does my driving behavior or the way I handle my trash make me part of a great and growing expression of commitment to preserve the planet? Is this a case where positive feedback can be truly regenerative?

Information about new ideas and emerging patterns needs to be accessible and individual voices need to be audible, but human computation may run the risk of simply reinforcing existing trends, which may be negative, by facilitating conformity. The popularity of SUVs and violent movies and games tends to be self-reinforcing and the most popular restaurant in town may not be the most pleasant place to go on a Saturday night. Simply waiting to see what "goes viral" on YouTube or Twitter is not sufficient. A noteworthy variation on regenerative feedback, however, is Kickstarter.com, which works like a chain letter to raise funds for nonprofit projects. 
Another significant trend related to Human Computation is the effort to create interactive contexts for the expression of greater diversity of knowledge and imagination. Interdisciplinary conferences (such as the Macy conferences on Cybernetics and on Group Process in the 1940s (Heims, 1991)) can be seen as an example of taking a group of individuals and turning them into a thinking system, a kind of superorganism (M.C.Bateson, 1972). With the decline in support for exploratory interdisciplinary work, there has been a rise in designs for interactive process in facilitating meetings, such as America Speaks, the $21^{\text {st }}$ century Town Hall Meeting format devised by Carolyn Lukensmeyer (Lykensmeyer, 2007) and Laura Chasin's Public Conversations Project (Herzig and Chasin, 2006), as well as research on conflict resolution and mediation (Fisher, 1991), (simultaneously alas with the steady increase in what Deborah Tannen calls the Argument Culture, in which issues are approached antagonistically (Tannen, 1998). Innovative techniques like brainstorming or open space exercises can themselves be regarded as technologies of human computation.

Human beings change in response to their habitual interactions, and there is already concern about possible deleterious effects of electronic communication, which will surely play a major role in human computation as we move forward. Much of human computation depends on persuading large numbers of individuals, acting separately, to contribute personal information, which is then combined, both processes facilitated by electronic technology. But it is important to notice that the implicit message of such an operation is membership in a larger whole. Any living system processes quantities of material and information, in ways that affect the state of that system and other systems to which it is connected, and attending to such processes potentially creates a sense of unity and an awareness of the reality of interdependence.

Emphasis on individualism has weakened for many people an understanding of what it means to be a part of some larger system, like the biosphere of this planet. We know today that our entire planet can be looked at as a living system (Lovelock, 1995) with some capacity for selfregulation, and that the circulation of water and atmospheric gases is such that disruption or pollution in one place on the planet has measurable effects elsewhere. Indeed, earth systems are far more closely integrated than the present human capacity to respond to them, even in the preparation for and response to major disasters. The American emphasis on individual autonomy is a product of the circumstances under which Europeans settled the North American continent, but it is descriptively inaccurate for the human condition and inhibits effective cooperation in problem solving and humanitarian relief as we experience and attempt to mitigate the global effects of climate disruption. Arguably, then, if increased reliance on human computation shifts attitudes away from the fetish of individual autonomy and teaches us, by implication, to recognize that we are connected parts of a larger whole, this is a goal to be pursued. Perhaps too, the awareness of inescapably "making a difference," for better or for worse, by our individual choices, will come to be seen as an essential aspect of human dignity as we learn that all of our choices count. 


\section{REFERENCES}

Bateson, M. C. (1972). Our Own Metaphor: A Personal Account of a Conference on the Effects of Conscious Purpose on Human Adaptation. New York: Alfred A. Knopf.

Bateson, M. C. (2013). Foreword: Making a Difference. In P. Michelucci (Ed.), Handbook of Human Computation (pp. 83-86). Springer New York.

Fisher, R., Ury, W. L., \& Patton, B. (1991). Getting to Yes: Negotiating Agreement Without Giving In (Revised edition.). New York, N.Y: Penguin Books.

Heims, S. J. (1991). The Cybernetics Group. Cambridge, Mass: The MIT Press.

Herzig, M. and Chasin, L. Fostering dialogue across divides: A nuts and bolts guide from the Public Conversations Project. Watertown, MA: The Public Conversations Project, 2006. Available at www.publicconversations.org

Holman, P., Devane, T., \& Cady, S. (2007). The Change Handbook: The Definitive Resource on Today's Best Methods for Engaging Whole Systems (2nd edition.). San Francisco: Berrett-Koehler Publishers.

Jackson, M. (2009). Distracted: the erosion of attention and the coming Dark Age. Amherst, N.Y.: Prometheus Books.

Lovelock, J. (1995). A New Look at Life on Earth. Oxford and New York: Oxford University Press.

Tannen, D. (1998). The Argument Culture: Moving from Debate to Dialogue (1st edition.). New York: Random House. 